mathematical deductions from premises based on some theoretical model used, perforce, in the absence of sounder quantum mechanical description. The elegance of the mathematics should not give the reader a false sense of security, nor blind him as to the possible inadequacies of a particular model in giving an accurate description of what may be a very complex physical situation, of which no mathematical description in olosed form may, in fact, be strictly possible.

E. P. WOHLFARTH

\section{METALLURGY AND ATOMIC THEORY}

Atomic Theory for Students of Metallurgy

By William Hume-Rothery. (Monographs and Report Series, No. 3.) Second (revised) edition. Pp. 331. (London: Institute of Metals, 1952.) $21 s$.

7 HE first edition of this book was published in 1 1946; it has since been reprinted twice, and now we welcome the appearance of a second edition in which several chapters have been amplified and brought up to date. It is an indication of the steady advance of the subject that a book of this kind, written primarily for honours degree students, should require such additions after so short a period; and the book itself is an indication of Dr. Hume-Rothery's determination to keep students of metallurgy abreast of developments in the fundamental aspects of their subject.

The recasting of this book has increased its size by forty-five pages, and meticulous care has been taken to present the latest data on each subject. For example, the old phase diagram of the coppergallium system, used primarily for the purpose of illustrating general principles, has been replaced by a later and presumably more accurate one. Again, in the general introduction of Chapter 1 and in the well-known table of electronic configurations, we now find data referring to the transuranic elements. Some of the most interesting of the new material which this edition contains is to be found in Chapter 27 and concerns the behaviour of what are called defect structures. These are alloys in which the electron concentration appropriate to the phase is maintained, during changes of composition, by the creation of vacant lattice sites.

Chapter 29 deals with the difficult problem of the transition elements, and has been considerably extended in the second edition. This is, perhaps, unfortunate. In the introduction to the first edition we are told that "it has been thought better to concentrate mainly on the properties for which the theories have provided a reasonably straightforward explanation, and to avoid those whose interpretation is still in doubt". However, in this chapter, and to some extent in the succeeding one, we find theories which, to put it mildly, have not received general acceptance and which, in truth, are based on vague and unsatisfactory concepts. It is, however, a great merit of this book that none of the theories presented is expressed dogmatically, and little harm should result to the intelligent student if, in fact, some of the hypotheses prove to be wide of the mark. Moreover, there can be no doubt whatever that great benefit will be derived by all who study this excellent book as a whole, and who appreciate its true purpose.

$$
\text { H. JoNES }
$$

\section{KINEMATICS OF MECHANISMS}

Kinematics of Mechanisms

By Dr. N. Rosenauer and Dr. A. H. Willis. Pp. 395. (Sydney: Associated General Publications Pty., Ltd., 1953.) $£(A) 410 s$.

DROF. ROSENAUER, who lectured on mechanism for many years in the University of Latvia, is now on the staff of the Now South Weles University of Technology. The many contributions he has made in this field have been published in various learned journals of Continental Lurope, where he enjoys a considerable reputation. This book is based upon his lectures and incorporates the fruits of much of his own research. It is a remarkable book in that it is the first publication on this topic which has appeared in the English language for a great many years. It is to be regretted, however, that the authors did not bear this fact in mind when writing it, for the British or American reader lacks the background possessed by his Continental counterpart, where the subject of kinematics has long been intensively studied. The approach adopted in Britain, in so far as the subject is treated at universities at all, is basically different : we do not lay much store by the extraordinarily thorough enumeration and examination of particular cases, so typical of German texts, to which this book is no exception. It is a large book and consequently costly; one feels convinced that if the material had been condensed to about one-third of its present bulk, and the price correspondingly reduced, the book would have gained not only in attractiveness but also in clarity, for fundamental methods and principles might thus have emerged from their present concealment.

One appreciates that it is a relatively novel departure for an Australian publisher to produce a scientific work of this magnitude, and since it is such a laudable venture one hesitates to criticize the production, which leaves something to be desired by British standards : the paper is not really suitable for printing fine line-blocks, of which there are nearly four hundred, and no attention has been paid to the size of lettering for the diagrams, in the light of their future photographic reduction for block-making. The result is that the letters vary in height on different diagrams between $1 / 16$ in. and $3 / 16$ in.

Although British and American work in this field is scarce enough, it is regrettable that the authors omit mention of even this little. Some of the work on kinematic chains published in Britain in $1950^{1}$ is more general and more elegant than that given in the chapter devoted to this topic. There is no mention of 3-dimensional- (or space-) mechanisms, though an introduction to this topic would have been valuable, especially as it is in this field that there has been much American and some British activity in recent years.

The somewhat academic Euler-Savary and Bobillier methods, which take up much space, might well be omitted or mentioned merely in passing. On the other hand it is most useful to have, for the first time in book form, an account of Prof. Rosenauer's use of orthogonal velocity vectors on which are based many of the constructions in this book.

The final chapter is entitled "An Introduction to the Synthesis of Mechanisms". To design a mechanism to meet a given specification is, of course, the engineer's whole object in studying the kinematics of mechanisms. One or more points of the mechanisms are required to approximate as closely as possible to 